\title{
Fuzzy net present value for engineering analysis
}

\author{
Mehdi Nosratpour $^{\mathrm{a}}$, Ali Nazeri ${ }^{\mathrm{b}}{ }^{*}$ and Hadi Meftahi ${ }^{\mathrm{c}}$
}

${ }^{a}$ Department of Management, University Technology Malaysia, Kuala Lumpur, Malaysia

${ }^{b}$ Department of Industrial Engineering, Damavand Branch, Islamic Azad University, Dmavand, Iran

${ }^{c}$ Department of industrial management, Payame Noor Universtiy, PO BOX 19395-3697, Tehran, Iran

\begin{tabular}{l}
\hline A R T I C L E I N F O \\
\hline Article history: \\
Received March 19, 2012 \\
Received in Revised form \\
April, 25, 2012 \\
Accepted 29 May 2012 \\
Available online \\
June 2 2012 \\
\hline Keywords: \\
Net present value \\
NPV \\
Fuzzy number \\
Fuzzy NPV
\end{tabular}
A B S T R A C T

\begin{abstract}
Cash flow analysis is one of the most popular methods for investigating the outcome of an economical project. The costs and benefits of a construction project are often involved with uncertainty and it is not possible to find a precise value for a particular project. In this paper, we present a simple method to calculate the net present value of a cash flow when both costs and benefits are given as triangular numbers. The proposed model of this paper uses Delphi method to figure out the fair values of all costs and revenues and then using fizzy programming techniques, it calculates the fuzzy net present value. The implementation of the proposed model is demonstrated using a simple example.
\end{abstract}

(c) 2012 Growing Science Ltd. All rights reserved.

\section{Introduction}

During the past few years, there have been many unpleasant macro-economical events, which have influenced financial figures significantly. European countries are facing with financial turmoil, their governments are not able to handle their liabilities, and they must go under sever cost reduction programs. In such circumstances, all capital budgeting analysis must consider uncertainty associated with the numbers. There are different methods for handling uncertainties in numbers such as stochastic programming, robust optimization and fuzzy programming. In fuzzy programming, we deal with numbers, which are more in terms of linguistic terms. Fuzzy programming helps us provide insight about the projects where there is no historical data. Fuzzy programming has been widely implemented in different areas of sciences.

Remer and Nieto (1995) presented 25 various techniques implemented to make an assessment the economic desirability of projects. They categorized these 25 methods into 5 types: net present value methods, rate of return methods, ratio methods, payback methods, and accounting methods. They

\footnotetext{
* Corresponding author. Tel: +989188410377

E-mail addresses: alinazeri_1979@yahoo.com (A. Nazeri) 
provided some insight into the advantages and limitations of these project evaluation methods by comparing and contrasting them.

Kahraman et al. (2000) made an assumption on vague input data and the fuzzy benefit-cost (B/C) ratio method was implemented to justify manufacturing technologies. After calculating the $\mathrm{B} / \mathrm{C}$ ratio based on fuzzy equivalent uniform annual value, they compared two assembly manufacturing systems having various life cycles. Kahraman et al. (2002) in another assignment provided formulas for the analyses of fuzzy present value, fuzzy equivalent uniform annual value, fuzzy future value, fuzzy benefit-cost ratio, and fuzzy payback period. They also examined cash flows to geometric and trigonometric cash flows and using these cash flows fuzzy present value, fuzzy future value, and fuzzy annual value formulas were developed for both discrete compounding and continuous compounding. Huang (2007) presented an investigation on capital budgeting problem with fuzzy investment outlays and fuzzy annual net cash flows based on credibility measure. Huang (2007) used net present value (NPV) method using two fuzzy chance-constrained programming models for capital budgeting problem. He also used a fuzzy simulation-based genetic algorithm to solve the resulted problem formulation and, using two numerical examples, the implementation of the method was presented and analyzed.

Sobel et al. (2009) formulated the problem of adaptively optimizing the expected present value of a project's cash flow, and explained that it is possible to perform the optimization. The formulation included randomness in activity durations, costs, and revenues, so the optimization leads to a recursion with a large state space even if the durations are exponentially distributed. They presented an algorithm that partially exercises the "curse of dimensionality" as computational results demonstrate.

Tsao (2012) presented a series of pragmatic algorithms to calculate NPV of capital investments in an environment, which are subject to uncertainty from randomness of outcomes and vagueness of estimation. He used linguistic terms to evaluate the possibilities of future economic scenarios, and fuzzy numbers were implemented to represent the linguistic assessments and estimate cash flows and costs of capital. He also utilized the standard fuzzy arithmetic in his method and presented the equations of the expected fuzzy NPV for a single project, expected fuzzy equivalent annuity for mutually exclusive projects with equal life spans, and expected fuzzy equivalent annuity to infinity for projects with unequal risks (jointly called expected FNPVs).

Liao and Ho (2010) proposed a fuzzy binomial approach, which could be implemented in project valuation under uncertainty. The proposed approach also discloses the value of flexibilities embedded in the project and provided a method to compute the mean value of a project's fuzzy NPV. The project's fuzzy NPV was characterized with right-skewed possibilistic distribution because these flexibilities keep the upside potential of profit but limit the downside risk of loss. Huang (2008) discussed the existing difficulties in an uncertain economic environment to forecast accurately the investment outlays and annual net cash flows of a project. Besides, available investment capital sometimes cannot be precisely given either.

Huang (2008) presented capital budgeting problem with fuzzy investment outlays, fuzzy annual net cash flows and fuzzy available investment capital based on credibility measure. Shahsavar et al. (2010) investigated the resource investment problem with discounted cash flows and generalized precedence relations under inflation factor. They attempt to detect activity schedules and resource requirement levels, which maximizes the NPV of the project cash flows. Sheen (2005) derived fuzzy NPV and pay back year techniques as decision indexes for cogeneration alternatives decision-making. They restricted the model to build the means and variances of the fuzzy indexes to rank various cogeneration alternatives. The mean and variance values depend only on the vertexes of the fuzzy index, and are independent of their height. The study also compared the results with simulating two numerical examples and by considering a cogeneration program in a petrochemical industry. The 
results indicated that the proposed fuzzy economic models provided consistent results with those of the conventional crisp models, and that the developed concepts could be easily implemented compared with the fuzzy ranking methods proposed in previous studies.

Ho and Liao (2011) presented a fuzzy method for investment project valuation in uncertain environments in terms of real options. They explained that the traditional methods were based on discounted cash flows (DCF) analysis, which were based on NPV and internal rate of return. However, DCF-based techniques provide two major pitfalls, where one is that DCF parameters such as cash flow approximation are imprecise in the uncertain decision making environments. The other issue is that the values of managerial flexibilities in investment projects are not precisely disclosed through DCF analysis. Both of them would entail improper outputs on strategic investment projects valuation. They proposed a fuzzy binomial approach, which could be implemented in project valuation under uncertainty. The proposed approach also disclosed the value of flexibilities embedded in the project. In addition, the proposed model provided a technique to measure the mean value of a project’s fuzzy expanded NPV, which represents the entire value of project.

Ustundag et al. (2010) introduced a systematic model for the economic analysis for RFID investment is proposed. In this approach, the elements of expenditure and benefits were determined to measure the value of an RFID investment. The Monte-Carlo simulation was implemented to find the expected NPV of RFID investment.

This paper presents a an approach based on NPV and fuzzy numbers to evaluate the present value of a project in triangular fuzzy number. The organization of this paper first presents some preliminary on fuzzy method in section 2. Section 3 demonstrates the implementation of the proposed model using a numerical example and the paper ends with concluding remarks.

\section{Fuzzy method}

Definition: $\tilde{M}$ is a left and right fuzzy number if there are functions for left (L) and right (R), respectively,

$\mu_{\tilde{M}}(x)= \begin{cases}L\left(\frac{m-x}{\alpha}\right) & x \leq m \\ R\left(\frac{x-m}{\beta}\right) & x>m\end{cases}$

where $m$ is a scalar and maintains an average of $\tilde{\mathrm{M}}$ and $\alpha, \beta>0$. We denote $\tilde{\mathrm{M}}$ as $(m, \alpha, \beta)_{L R}$. The LR fuzzy numbers have the following characteristics,

1. $\mathrm{L}$ and $\mathrm{R}$ are non-increasing functions of $R^{+} \rightarrow[0,1]$.

2. $L(0)=R(0)=1$.

3. $L(x)<1, R(x)<1 \quad \forall x>0$

4. $L(x)>0, R(x)>1 \quad \forall x<1$

5. $L(1)=R(0)=0$

Definition: A fuzzy triangular $\tilde{\mathrm{M}}=\left(\alpha_{1}, \alpha_{2}, \alpha_{3}\right)$ is stated as follows, 
$\mu_{\tilde{M}}(x)=\left\{\begin{array}{cc}0 & x<a_{1} \\ \frac{x-a_{1}}{a_{2}-a_{1}} & a_{1} \leq x \leq a_{2} \\ \frac{a_{3}-x}{a_{3}-a_{2}} & a_{2} \leq x \leq a_{3} \\ 0 & x>a_{3}\end{array}\right.$

\subsection{Fuzzy net present value}

In traditional NPV problems, the cash flow diagram consists of different numbers in crisp format. For instance, we know exactly how much we should invest on a particular construction project within time horizon but in real-world case studies, construction materials are subject to uncertainties and it is not possible to assign a precise value to each cash flow item. Therefore, we may ask some experts to determine the cost of a project, separately through a Delphi process. Next, we gather all feedbacks from experts and inform the numbers to experts asking them to reconsider their numbers based on what the other people think and this process is repeated until we reach some common factors. The following summarizes details of our fuzzy survey,

Stage 1. Assign three the lowest $\left(a_{1}^{i}\right)$, most probable $\left(a_{M}^{i}\right)$ and the highest $\left(a_{2}^{i}\right)$ values to $E_{i}, i=1, \cdots, n$ and state the numbers as $A_{i}=\left(a_{1}^{i}, a_{M}^{i}, a_{2}^{i}\right) \quad i=1,2, \ldots, n$

Stage 2. Calculate $A_{\text {ave }}=\left(m_{1}, m_{M}, m_{2}\right)$ for all $A_{i}$ and for each expert's opinion we calculate the deviation between $A_{a v e}$ and $A_{i}$ and report it to expert.

Stage 3. Each expert provides a new triangular number as $B_{i}=\left(b_{1}^{i}, b_{M}^{i}, b_{2}^{i}\right)$

Stage 4. Replace $a_{1}^{i}, a_{M}^{i}, a_{2}^{i}$ with $b_{1}^{i}, b_{M}^{i}, b_{2}^{i}$ and go to stage 2 until there is a negligible difference between the new triangular fuzzy numbers and the older ones.

In order to calculate the fuzzy net present value (FNPV), let $\mathrm{L}$ be the smallest possible value, $\mathrm{M}$ be the mean or most promising value, $\mathrm{R}$ be the largest possible value, $\mathrm{F}$ be the cash flow, $i$ be the interest rate and $(\mathrm{n}, \mathrm{t})$ be the time, respectively. The factor to calculate the present value of a particular future revenue (F) with interest rate $i$ after $n$ periods is $(P / F, i, n)=(1+i)^{-n}$. Therefore, to calculate $F N P V=\left(N P V_{L}, N P V_{M}, N P V_{R}\right)$ we use the following,

$$
\begin{aligned}
& N P V_{L}=F_{0}^{L}+\sum_{t=1}^{n} F_{t}{ }^{L} \begin{cases}\prod_{t=1}^{n}\left(P / F, i_{t}^{L}, 1\right) & F_{t}{ }^{L}<0 \\
\prod_{t=1}^{n}\left(P / F, i_{t}^{R}, 1\right) & F_{t}{ }^{L}>0\end{cases} \\
& N P V_{M}=F_{0}^{M}+\sum_{t=1}^{n} F_{t}{ }^{M} \prod_{t=1}^{n}\left(P / F, i_{t}^{M}, 1\right) \\
& N P V_{R}=F_{0}{ }^{R}+\sum_{t=1}^{n} F_{t}{ }^{R} \begin{cases}\prod_{t=1}^{n}\left(P / F, i_{t}^{L}, 1\right) & F_{t}{ }^{R}>0 \\
\prod_{t=1}^{n}\left(P / F, i_{t}^{R}, 1\right) & F_{t}{ }^{R}<0\end{cases}
\end{aligned}
$$

Note that in order to calculate the difference between two numbers $\tilde{M}=\left(a_{L}, a_{M}, a_{R}\right)$ and $\tilde{N}=\left(b_{L}, b_{M}, b_{R}\right)$ we use the following, 
$S(\tilde{M}, \tilde{N})=\frac{\left(a_{L}+2 a_{M}+a_{R}\right)-\left(b_{L}+2 b_{M}+b_{R}\right)}{4}$.

For more details, the interested readers are referred to Zadeh (1975a-c) and Zimmermann (1996).

\section{Numerical example}

Consider the following numerical example shown in Fig. 1.

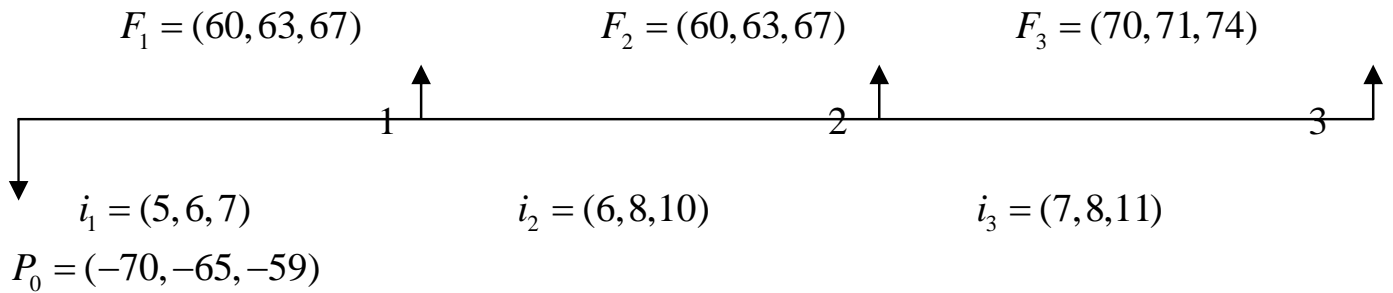

Fig. 1. Cash flow diagram for numerical example

As we can observe from the Fig. 1 , the cash flow needs an initial investment of $\mathrm{P}_{0}=(-70,-65,-59)$ with three positive returns. Using Eqs. (3-7) yields FNPV= $(87,104,123)$.

\section{Conclusion}

In this paper, we have presented a simple but sophisticated method to calculate the net present value of a cash flow where both the costs and benefits of building a project are subject to uncertainty. The proposed model of this paper considers all expenditures and revenues in terms of triangular fuzzy numbers and based on fuzzy theory, we calculate the fuzzy net present value. The main advantage of using such methodology is to have more sophisticated final figures for net present value, which incorporates the least probable, more likely and the highest possible values.

\section{Acknowledgment}

The authors would like to thank the anonymous referees for their constructive comments on earlier version of this work.

\section{References}

Ho, S.H., \& Liao, S.H. (2011). A fuzzy real option approach for investment project valuation. Expert Systems with Applications, 38(12), 15296-15302

Huang, X. (2007). Chance-constrained programming models for capital budgeting with NPV as fuzzy parameters. Journal of Computational and Applied Mathematics, 198(1), 149-159.

Huang, X. (2008). Mean-variance model for fuzzy capital budgeting. Computers \& Industrial Engineering, 55(1), 34-47.

Kahraman, C., Tolga, E., \& Ulukan, Z. (2000). Justification of manufacturing technologies using fuzzy benefit/cost ratio analysis. International Journal of Production Economics, 66(1), 45-52.

Kahraman, C., Ruan, D., \& Tolga, E. (2002). Capital budgeting techniques using discounted fuzzy versus probabilistic cash flows. Information Sciences, 142(1-4), 57-76.

Liao, S.H., \& Ho, S.H. (2010). Investment project valuation based on a fuzzy binomial approach. Information Sciences, 180(11), 2124-2133.

Remer, D.S., \& Nieto, A.P. (1995). A compendium and comparison of 25 project evaluation techniques. Part 1: Net present value and rate of return methods. International Journal of Production Economics, 42(1), 79-96.

Shahsavar, M., Akhavan Niaki, S.T., \& Najafi, A.A. (2010). An efficient genetic algorithm to maximize net present value of project payments under inflation and bonus-penalty policy in resource investment problem. Advances in Engineering Software, 41(7-8), 1023-1030. 
Sheen, J.N. (2005). Fuzzy evaluation of cogeneration alternatives in a petrochemical industry. Computers \& Mathematics with Applications, 49(5-6), 741-755

Sobel, M.J., Szmerekovsky, J.G., \& Tilson, V. (2009). Scheduling projects with stochastic activity duration to maximize expected net present value. European Journal of Operational Research, 198(3), 697-705.

Tsao, C.T. (2012). Fuzzy net present values for capital investments in an uncertain environment. Computers \& Operations Research, 39(8), 1885-1892.

Ustundag, A., Kılınç, M.S., \& Cevikcan, E. (2010). Fuzzy rule-based system for the economic analysis of RFID investments. Expert Systems with Applications, 37(7), 5300-5306

Zimmermann, H.J (1996). Fuzzy Set Theory. $3^{\text {rd }}$ ed., Kluwer academic publisher.

Zadeh, A. (1975a). The concept of a linguistic variable and its application to approximate reasoning, part 1. Information Sciences, 8(3), 199-249.

Zadeh, A. (1975b). The concept of a linguistic variable and its application to approximate reasoning, part 2. Information Sciences, 8(4), 301-357.

Zadeh, A. (1975c). The concept of a linguistic variable and its application to approximate reasoning, part 3. Information Sciences, 9(1), 43-58. 